\title{
Naringenin Ameliorated Kidney Injury through Let-7a/TGFBR1 Signaling in Diabetic Nephropathy
}

\author{
Ning Yan, ${ }^{1}$ Li Wen, ${ }^{1,2}$ Rui Peng, ${ }^{3}$ Hongmei Li, ${ }^{4}$ Handeng Liu, \\ Huimin Peng, ${ }^{1}$ Yan Sun, ${ }^{1}$ Tianhui Wu, ${ }^{1}$ Lei Chen, ${ }^{5}$ Qingrui Duan, ${ }^{5}$ \\ Yixuan Sun, ${ }^{5}$ Qin Zhou, ${ }^{5}$ Lijiang Wei, ${ }^{6}$ and Zheng Zhang ${ }^{1,2}$ \\ ${ }^{1}$ Molecular Medicine and Cancer Research Center, Chongqing Medical University, Chongqing 400016, China \\ ${ }^{2}$ Department of Cell Biology and Genetics, Chongqing Medical University, Chongqing 400016, China \\ ${ }^{3}$ Department of Bioinformatics, Chongqing Medical University, Chongqing 400016, China \\ ${ }^{4}$ Chongqing Red Cross Hospital, Chongqing 400016, China \\ ${ }^{5}$ The Second Clinical College, Chongqing Medical University, Chongqing 400016, China \\ ${ }^{6}$ The First Clinical College, Chongqing Medical University, Chongqing 400016, China
}

Correspondence should be addressed to Zheng Zhang; zhangzheng92@163.com

Received 1 April 2016; Revised 25 May 2016; Accepted 1 June 2016

Academic Editor: Mark A. Yorek

Copyright (C) 2016 Ning Yan et al. This is an open access article distributed under the Creative Commons Attribution License, which permits unrestricted use, distribution, and reproduction in any medium, provided the original work is properly cited.

\begin{abstract}
Diabetic nephropathy (DN) is one of the most common complications of diabetes mellitus (DM). However, the exact mechanism is not clearly understood. In this study, our results showed that $24 \mathrm{~h}$ urinary protein, kidney index, and glomerular area were decreased, while creatinine clearance ratio was increased in DN rats when the rats were treated with NAR $50 \mathrm{mg} / \mathrm{d}$ for 6 weeks. Mesangial cell (MMCs) proliferation was inhibited in the NAR group by 3,(4,5-dimethyl-2-thiazolyl)-2,5-diphenyl-2H-tetrazolium bromide (MTT), and the cell cycle analysis showed that cells stayed in G2 phase in NAR group. And NAR treatment attenuated the deposition of ECM in DN rats and MMCs. Moreover, our data showed that let-7a was downexpressed in both DN rats and MMCs under high glucose condition. Surprisingly, NAR affected the expressions of Col4 and FN through upregulating let-7a in MMCs. In addition, we found that let-7a negatively regulated the expression of transforming growth factor- $\beta 1$ receptor 1 (TGFBR1), and TGFBR1 was required for the let-7a-mediated downregulation of TGF- $\beta 1 /$ smad signaling. Interestingly, NAR inhibited TGF$\beta 1 /$ smads signaling activation by upregulating let-7a. Therefore, our findings indicated that NAR ameliorated kidney injury by regulating let-7a/TGFBR1 signaling.
\end{abstract}

\section{Introduction}

Diabetic nephropathy (DN) is the leading cause of endstage renal disease. Mesangial cell proliferation, excessive extracellular matrix (ECM) proteins accumulation, basement membrane thickening, mesangial expansion, and other mesangial region lesions are involved in the renal pathological process, which ultimately lead to glomerular sclerosis. Although hyperglycemia, hyperlipemia, hypertension, blood flow, and inflammation are participated in the pathogenesis of DN, the exact cause of DN remains unclear [1-4].

Naringenin (4,5,7-trihydroxy flavanone, NAR) is a flavanone compound found in citrus fruits, which is rich in the seeds and peels of fruits. Recent researches showed that NAR had many potentially pharmacological effects such as antioxidant, anti-inflammation, anticancer, and antifibrosis [5-8]. Meanwhile, it was reported that NAR possessed antiproliferative activity in lung cancer, colorectal cancer, and leukemia cell and regulated extracellular matrix synthesis in hepatic satellite cell [9-12]. Furthermore, NAR could decrease the blood glucose level in STZ induced diabetic rats $[13,14]$, suppress macrophage infiltration into adipose tissue in an early phase of high-fat diet-induced obesity [15], and inhibit production of IL-1 $\beta$, IL-6, type IV collagen, fibronectin, TGF- $\beta 1$, and monocyte chemoattractant protein-1 (MCP-1) 
in the kidney of diabetic mice [16]. However, the mechanism of the proliferation effect of NAR in DN is unknown up to now.

MicroRNA let-7 and its family members have been reported to participate in many diseases including kidney diseases. Let-7a regulated glucose metabolism and insulin synthesis/secretion with type 2 DM by targeting lin 28 pathway $[17,18]$. Let-7a and let-7d could affect glucose metabolism by downregulating IL-13 in the skeletal muscle of type 2 DM patients [19]. Also, let-7 family members regulated collagen expression in glomerular mesangial cells under diabetic conditions [20]. Furthermore, our previous experiments showed that let-7a was downexpressed in DN patients, and the let-7a-3 promoter hypermethylation and the rs1143770 polymorphism of let-7a-2 were participated in DN [21, 22]. Moreover, let-7a had been reported to modulate ECM deposition in breast and pancreas cells [23-25]. These findings suggested that let-7a may be an important factor in the effects of NAR in DN.

In the present study, we aimed to explore the protective effects of NAR on kidney as well as its effects on let-7a/ TGFBR1 signaling in diabetic nephropathy rats and mesangial cell under high glucose condition. This study demonstrated that let-7a and its related pathway-TGF- $\beta 1 /$ smad signaling formed a negative feedback to inhibit the deposition of ECM by targeting TGFBR1 in DN. Moreover, NAR might repress glomerular mesangial cells proliferation and accumulation of ECM by let-7a/TGFBR1 signaling in DN, and let-7a may be a novel potential target for NAR protecting against diabetic nephropathy.

\section{Materials and Methods}

2.1. Animal Experiments. Twenty-five male Sprague-Dawley rats weighting $120 \pm 20 \mathrm{~g}$ (four weeks old) were provided by the Experimental Animal Center at Chongqing Medical University. The animals were housed in the clean environment under conditions of controlled temperature of $20-25^{\circ} \mathrm{C}$ and humidity $65 \sim 69 \%$. The rats were randomly divided into a control group (CON, $n=5)$ and a DN group $(n=20)$. The control rats were fed with the normal diet, while the rats in diabetic group were fed with the high-sugar-high-fat diet. Five weeks later, diabetic nephropathy was induced by a single intraperitoneal injection of STZ (Sigma, St. Louis, MO, USA) $(30 \mathrm{mg} / \mathrm{kg})$ [26]. High blood glucose level of Tail vein (fasting glucose $>16.7 \mathrm{mmol} / \mathrm{L}$ ) and high urinary total protein level (total protein level in DN group was more than twice higher than the control group) were measured to confirm early DN in rats [27]. Then, the DN rats $(n=18)$ were assigned into two groups: $\mathrm{DN}$ rats treated with saline (DN group, $n=8$ ) and DN rats treated with NAR (NAR group, $n=10$ ). The rats in NAR group were treated with naringenin (Sangon, Shanghai, China) (50 mg. $\mathrm{kg}^{-1} \cdot \mathrm{day}^{-1}$, gavage), while the rats in DN group were treated with the equal volume of normal saline. Among the three groups, blood glucose was measured each week, and $24 \mathrm{~h}$ urine was collected every two weeks. Six weeks after NAR treatment, the rats were sacrificed. Heart blood and $24 \mathrm{~h}$ urine were collected for creatinine detection.
Renal tissues from each rat were disposed as follows: one was immediately frozen in liquid nitrogen, and the other was fixed with $4 \%$ paraformaldehyde. All animal experiments were performed in accordance with the protocols approved by Chongqing Medical University Animal Care Committee.

2.2. Biochemical and Histology Assays. Blood glucose was measured by Bayer glucometer. $24 \mathrm{~h}$ urinary protein was measured by the coomassie brilliant blue (CBB) method. Urinary creatinine (Ucr) and serum creatinine (Scr) were measured by clinical laboratory. Urinary creatinine clearance (Ccr) ratio was calculated using the following equation: $\mathrm{Ccr}$ $\left(\mathrm{mL} \cdot \mathrm{min}^{-1} \cdot \mathrm{kg}^{-1}\right)=[$ urinary $\mathrm{Cr}(\mathrm{mmol} / \mathrm{L}) \times$ urinary volume $(\mathrm{mL})$ /serum $\mathrm{Cr}(\mathrm{mmol} / \mathrm{L})] \times[1 / 1,440(\mathrm{~min})]$ [28]. Right kidney weight $(\mathrm{KW})$ and body weight $(\mathrm{BW})$ were assessed to calculate kidney index: $\mathrm{KI}=\mathrm{KW} / \mathrm{BW} \times 1000$. Kidney tissue paraffin sections were subjected to hematoxylin-eosin (HE) staining. The glomerular areas $\left(\mu \mathrm{m}^{2}\right)$ with 50 fields of view were analyzed by Image-Pro plus 6.0.

2.3. Cell Culture. 0.1 g NAR powder was dissolved in $1 \mathrm{~mL}$ DMSO and then filtrated using $0.22 \mu \mathrm{m}$ micropore filter, preserved at $4^{\circ} \mathrm{C}$ for subsequent use. The solution were diluted in DMEM to different working concentration of $100 \mu \mathrm{mol} / \mathrm{L}, 200 \mu \mathrm{mol} / \mathrm{L}, 400 \mu \mathrm{mol} / \mathrm{L}, 600 \mu \mathrm{mol} / \mathrm{L}$, and $1000 \mu \mathrm{mol} / \mathrm{L}$. Mouse glomerular mesangial cell (MMC) line (Academy of Sciences, Shanghai, China) was cultured in DMEM with $20 \%$ FBS in a humidified atmosphere containing $5 \% \mathrm{CO}_{2}$ at $37^{\circ} \mathrm{C}$. MMCs were maintained in $5 \mathrm{mmol} / \mathrm{L}$ glucose plus $20 \mathrm{mmol} / \mathrm{L}$ mannitol as the control group (LG). Cells were maintained in $25 \mathrm{mmol} / \mathrm{L}$ glucose as the high glucose group (HG), and cells were treated with $25 \mathrm{mmol} / \mathrm{L}$ glucose plus NAR as the NAR treatment group (NAR).

293T cells were preserved in our laboratory and grown in DMEM with $10 \%$ FBS as previously described.

2.4. MTT Assay. MMCs were seeded at a density of $1.0 \times 10^{4}$ cells/well in 96-well plates with NAR treatment. After treated with NAR for $0 \mathrm{~h}, 12 \mathrm{~h}, 24 \mathrm{~h}$, and $36 \mathrm{~h}, 20 \mu \mathrm{L}$ MTT reagent was added into each corresponding cultured well. Incubate 4 hours in $5 \% \mathrm{CO}_{2}$ environment at $37^{\circ} \mathrm{C}$. The absorbance in $490 \mathrm{~nm}$ was measured by the microplate reader (Bio-Rad, USA).

2.5. Flow Cytometry Assay. MMCs were treated with NAR for $24 \mathrm{~h}$, then were digested with trypsin and were made into cell suspension, were washed with precooling PBS twice, were fixed with $75 \%$ precooling ethanol overnight at $4^{\circ} \mathrm{C}$, collected the cells by centrifuge, were washed with $1 \mathrm{~mL}$ PBS, were added $100 \mu \mathrm{L}$ RNaseA incubated at $37^{\circ} \mathrm{C}$ for $30 \mathrm{~min}$, were added $400 \mu \mathrm{L}$ PI incubated at $4^{\circ} \mathrm{C}$ for $30 \mathrm{~min}$ at dark, $1 \times$ $10^{4}$ cells for cell cycle analysis with BD flow cytometry by standard procedure.

2.6. Let-7a Transfection Experiments. MMCs were seeded at a density of $0.75 \times 10^{6}$ cells $/ \mathrm{mL}$ in serum-free DMEM, with the addition of a transfection agent and let-7a mimics 
oligonucleotides (let7a-M), negative control mimics (NC$\mathrm{M})$, let-7a inhibitor oligonucleotides (let7a-I), and negative control inhibitor (NC-I) (Jima, Shanghai, China). Six hours after transfection, the medium was changed and the cells were incubated with fresh serum-containing medium for another $24 \sim 48 \mathrm{~h}$. In addition, MMCs were transfected with let-7a mimics plus NAR as the NAR + let7a-M group; cells were transfected with let-7a inhibitor plus NAR as the NAR + let7aI group. All transfections were performed with the aid of a lipofectamine 2000 transfection agent (Invitrogen, USA) following the manufacturer's instructions. Transfected cells were harvested at the indicated times for RNA and protein isolation.

2.7. Real-time RT PCR. Total RNA was extracted by Trizol reagent (Invitrogen) according to the manufacturer's instructions. Small RNAs $(<300 \mathrm{nt})$ were isolated when 2 to $5 \mu \mathrm{g}$ total RNA sample was size-fractionated using a YM-100 Microcon centrifugal filter (Millipore). The PrimeScript RT reagent Kit (Takara, Dalian, China) and SYBR Premix Ex Taq TM II (Takara, Dalian, China) were used for miRNA and mRNA quantification. Relative expressions were calculated using $2^{-\triangle \Delta C T}$ method and normalized to the expression of U6 or GAPDH. Primers for real-time PCR were as follows: Col-4, (F): $5^{\prime}$-CAAACCACAGCCAATCCTTCA-3', (R): $5^{\prime}$-AAGAAGGGAAAACCCACTGTAGAGT- ${ }^{\prime}$; FN, F: $5^{\prime}$ CATGGCTTTAGGCGAACCA-3' ${ }^{\prime}$, R: $5^{\prime}$-CATCTACATTCGGCAGGTATGG- $3^{\prime}$; TGF- $\beta 1$, F: $5^{\prime}$-AGGGCTACCATGCCAACTTC- ${ }^{\prime}$, R: $5^{\prime}$-CCACGTAGTAGACGATGGGC-3'; TGFBR1, F: 5' -TGGCGGAATCCACGAAGA-3', R: 5' -ACGGATGGATCAGAAGGTACAAG-3' ${ }^{\prime}$; Smad2, F: $5^{\prime}$ - ACAACAGGCCTTTACAGCTTC-3', R: 5' -CTCTGTGGCTCAATTCCTGC-3'; Smad7, F: $5^{\prime}$-CCATCAAGGCTTTTGACTATGAAA-3 ${ }^{\prime}$, R: $5^{\prime}$-CCATGGCTGCTGCATGAAC- $3^{\prime}$. All real-time RT PCR was performed in triplicate, and the data were presented as means $\pm \mathrm{SD}$.

2.8. Western Blotting. Total protein from cells and renal tissues were extracted, subjected to $10 \%$ SDS-polyacrylamide gels (Beyotime, Shanghai, China) and transferred to polyvinylidene difluoride membrane. Membranes were blocked with 5\% nonfat dry milk dissolved in TBST and then incubated with primary antibody overnight at $4^{\circ} \mathrm{C}$. Antibodies and dilutions included the following: rabbit monoclonal to Col4 antibody (1:1,000, Proteintech), rabbit polyclonal to FN antibody $(1: 1,000$, Proteintech), rabbit monoclonal to smad2 antibody (1:1,500, Proteintech), rabbit polyclonal to $\mathrm{p}$-smad2 antibody (1:500, Bioworld), rabbit polyclonal to TGF- $\beta 1$ antibody (1:800, Proteintech), rabbit polyclonal to TGFBR1 antibody (1:700, Bioworld), and rabbit polyclonal to GAPDH antibody $(1: 2,000$, Proteintech). The membranes were incubated with the goat anti-rabbit IgG $(1: 5,000$, Abcam $)$ for $1.5 \mathrm{~h}$. Signals were detected with ChemiDocXRS system (Bio-Rad, USA). Grey values of protein bands were analyzed by Quantity One software.

2.9. Immunofluorescence. Kidney tissue paraffin sections $(4 \mu \mathrm{m})$ were subjected to immunofluorescence staining.
Antibodies and dilutions were as follows: rabbit monoclonal to Col4 antibody (1:50, Proteintech), rabbit polyclonal to FN antibody (1:100, Proteintech), rabbit polyclonal to TGF$\beta 1$ antibody (1:50, Proteintech), and rabbit polyclonal to TGFBR1 antibody (1:50, Bioworld). The tissue sections were then incubated with FITC or TRITC for $1 \mathrm{~h}$. Images were acquired using the fluorescence microscope (Olympus Japan).

2.10. 3'-UTR-Luciferase-Reporter Analysis. TGFBR1 (NM 009370.2) 3'-UTR-luciferase constructs were made using the pmiR-RB-REPORT ${ }^{\mathrm{TM}}$ vector, and the primers for TGFBR1 $3^{\prime}$ UTR-wt were as follows: TGFBR1-wt-F: $5^{\prime}$ GCGCTCGAGGGGTGTTTAGGAGGCTGGT-3'; TGFBR1wt-R: $5^{\prime}$-AATGCGGCCGCCATACAACTTTTCCTTCGG$3^{\prime}$. The PCR products were excised with NotI and XhoI. The potential binding sequences of let-7a on the TGFBR1 $3^{\prime}$ UTR were mutated by the QuikChange ${ }^{\mathrm{TM}}$ Site-Directed Mutagenesis Kit (Stratagene). For transfection, 293T cells were seeded into 96-well plates at a density of $1.5 \times 10^{4}$ per well; then cells were transfected with TGFBR1-3'UTR-wt (200 ng/mL), TGFBR1-3'UTR-mut $(200 \mathrm{ng} / \mathrm{mL})$, and let-7a mimics $(50 \mathrm{nmol} / \mathrm{L})$ using lipofectamine ${ }^{\mathrm{TM}} 2000$. After $48 \mathrm{~h}$, cells were lysed and assayed for luciferase activities. The ratio of firefly to Renilla activity was calculated. All experiments were performed in triplicate.

2.11. Statistical Analysis. All statistical tests were performed by SPSS19.0. Data for multiple variable comparisons were analyzed by one-way analysis of variance (ANOVA). Results were presented as means $\pm \mathrm{SD}$. Statistical significance was accepted at the 95\% confidence level $(p<0.05)$.

\section{Results}

3.1. Effects of NAR on Blood Glucose Level and Renal Function and Morphology in DN Rats. Results showed blood glucose level went up steadily with time in DN rats, while blood glucose level was decreased at 6 weeks in NAR group (Figure $1(\mathrm{a})$ ). The $24 \mathrm{~h}$ urinary protein went up steadily with time in DN rats, while after NAR treatment, it was decreased (Figure 1(b)). And creatinine clearance ratio (Ccr) is generally considered as the feature of renal function, reflecting renal filtration function. Kidney index (KI) and glomerular area (GA) are the morphological markers of glomerular hypertrophy. We evaluated the effects of NAR on $24 \mathrm{~h}$ urinary protein, $\mathrm{Ccr}, \mathrm{KI}$, and GA. $24 \mathrm{~h}$ urinary protein $(8.49 \pm 1.87$ versus $40.41 \pm 4.68 \mathrm{mg} / 24 \mathrm{~h}, p<0.001)$. KI $(2.87 \pm 0.17$ versus $4.83 \pm 0.30, p<0.001)$ and GA $(146.32 \pm 23.74$ versus $\left.194.29 \pm 40.60 \mu \mathrm{m}^{2}, p<0.05\right)$ were significantly increased in $\mathrm{DN}$ group compared with those in CON group, whereas Ccr $(3.31 \pm 0.74$ versus $1.39 \pm 0.30 \mathrm{~mL} / \mathrm{min}, p<0.01)$ was decreased in DN group. After treatment with NAR, Ccr was obviously increased $(1.39 \pm 0.30$ versus $2.08 \pm 0.55 \mathrm{~mL} / \mathrm{min}$, $p<0.05$ ) (Figure 1(c)); KI was significantly decreased (4.83 \pm 0.30 versus $4.33 \pm 0.34, p<0.05$ ) (Figure $1(\mathrm{~d})$ ). GA was reduced $\left(194.29 \pm 40.60\right.$ versus $165.15 \pm 41.15 \mu \mathrm{m}^{2}, p<$ $0.05)$ in the NAR group compared with that in DN group 


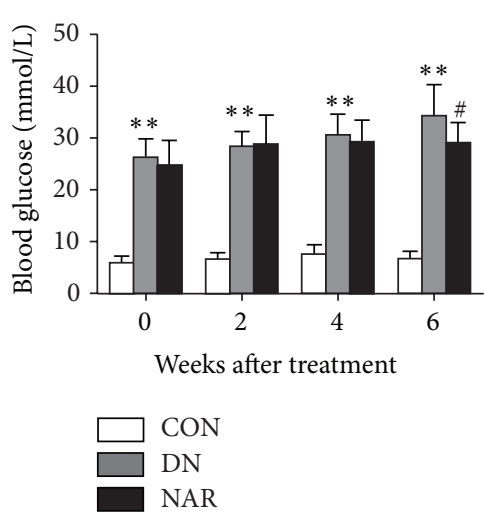

(a)

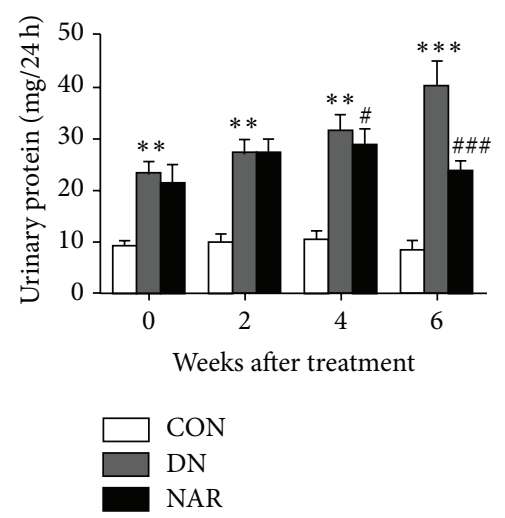

(b)

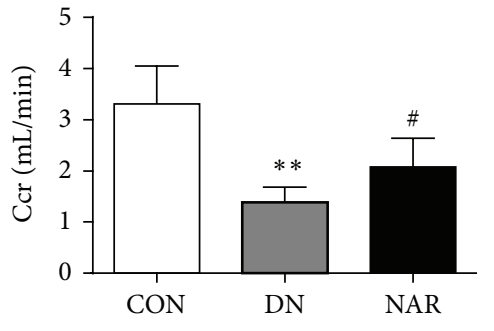

(c)

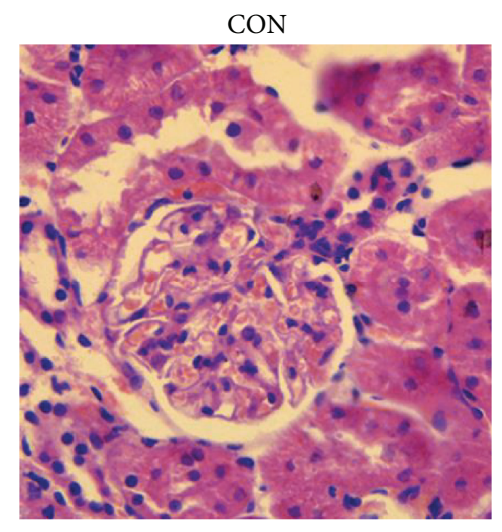

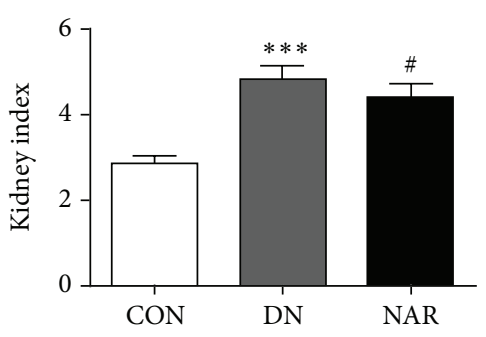

(d)

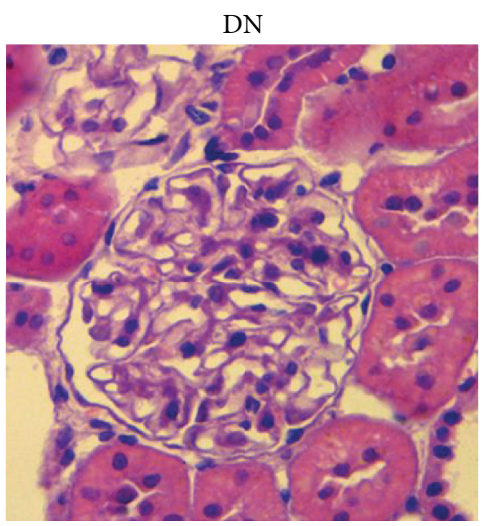

(f)

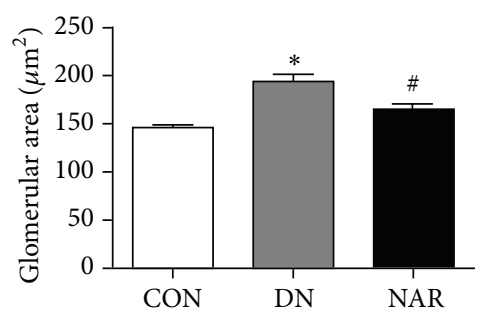

(e)

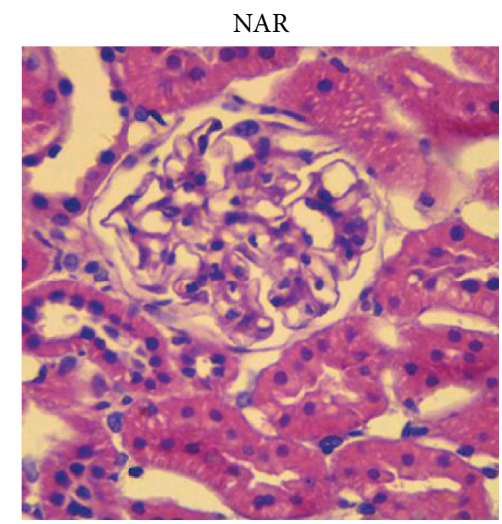

FIGURE 1: Effects of NAR on renal morphology and functions in diabetic rats. (a) Blood glucose level, (b) 24 h urinary protein, (c) urinary creatinine clearance ratio (Ccr), (d) kidney index (KI) which equals right kidney weight/body weight $\times 1000$, (e) glomerular area (GA), and (f) representative photograph for hematoxylin-eosin $(\mathrm{HE}, \times 400)$ are shown. Results are expressed as mean \pm standard deviation, CON $(n=5)$, DN $(n=7)$, and NAR $(n=8)$. (a-d ${ }^{*} p<0.05,{ }^{* *} p<0.01$, and ${ }^{* * *} p<0.001$ versus CON group; ${ }^{\#} p<0.05,{ }^{\# \#} p<0.01$, and ${ }^{\# \# \#} p<0.001$ versus DN group.

(Figures 1(e) and 1(f)). Together, our results suggested that NAR ameliorated renal structure and function.

\subsection{Effects of NAR on Cell Proliferation, Cell Cycle, and} Expressions of Col4 and FN. Excessive mesangial cells proliferation increased the production of ECM. To evaluate the effect of NAR on mesangial cells proliferation, MTT and cell cycle analysis were used. MTT results showed that NAR obviously inhibited cell proliferation at the concentration of 400,600 , and $1000 \mu \mathrm{mol} / \mathrm{L}$ for $24 \mathrm{~h}, 36 \mathrm{~h}$, and $200 \mu \mathrm{mol} / \mathrm{L}$ for $36 \mathrm{~h}$, whereas cell proliferation rates were unchanged at the concentration of $100 \mu \mathrm{mol} / \mathrm{L}$ (Figure 2(a)). Moreover, the cell cycle analysis showed cells were treated with 400, 600, and $1000 \mu \mathrm{mol} / \mathrm{L}$ NAR for $24 \mathrm{~h}$, respectively. The results showed that G2 phase of NAR group was significantly increased when compared with that in $\mathrm{HG}$ group, while $\mathrm{S}$ phase was shortened in NAR group at the concentration of 600 and $1000 \mu \mathrm{mol} / \mathrm{L}$. Therefore, these data indicated that NAR delayed mesangial cell growth at G2 phase (Figure 2(b)).

A key feature of DN was the accumulation of excessive extracellular matrix proteins, predominant collagens (Col4), and fibronectin (FN). To determine whether NAR affected Col4 and FN expression in vivo and in vitro, Col4 and FN mRNAs and proteins of kidney tissues were examined by real-time RT PCR (Figure 2(c)), western blot (Figures 2(d), 


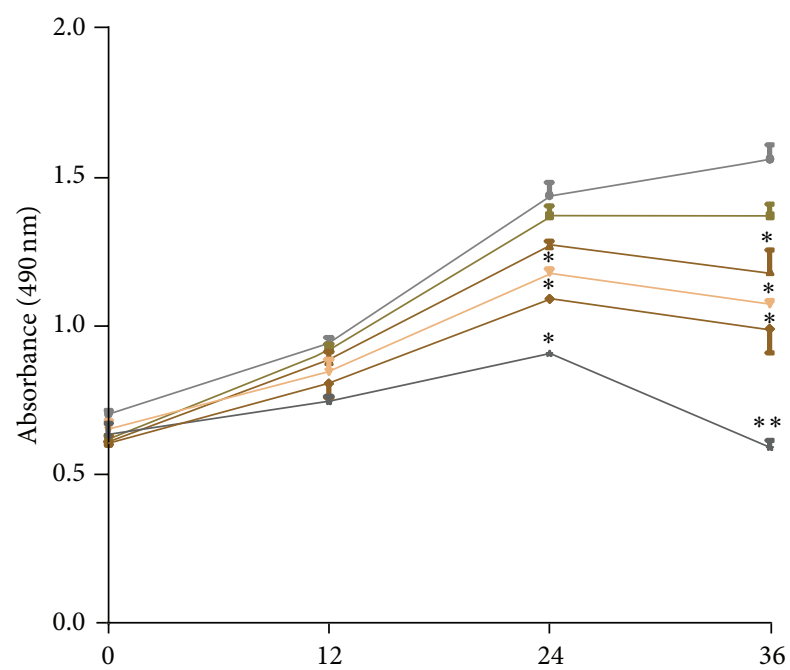

(h)

(a)

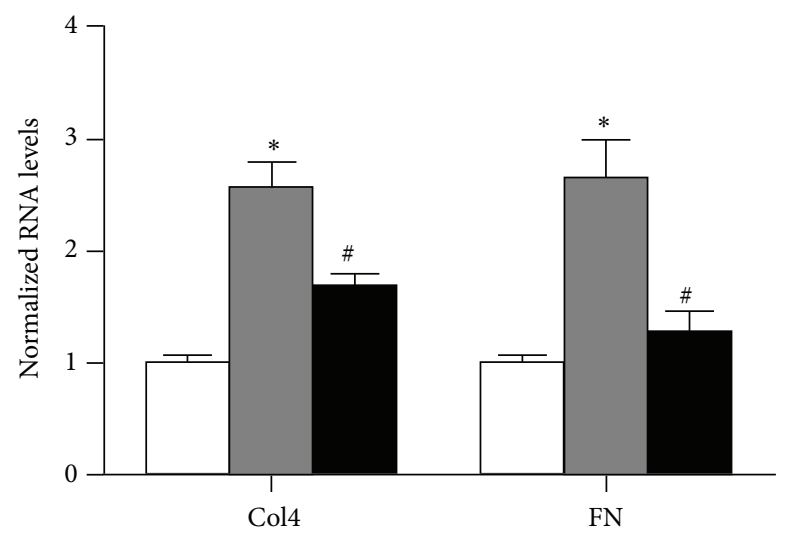

$\square \mathrm{CON}$

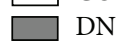

NAR

(c)

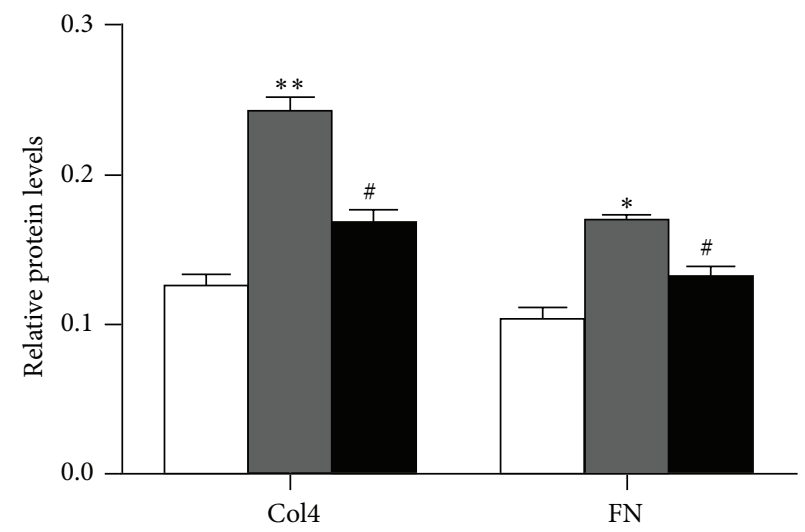

$\square$ CON
DN

NAR

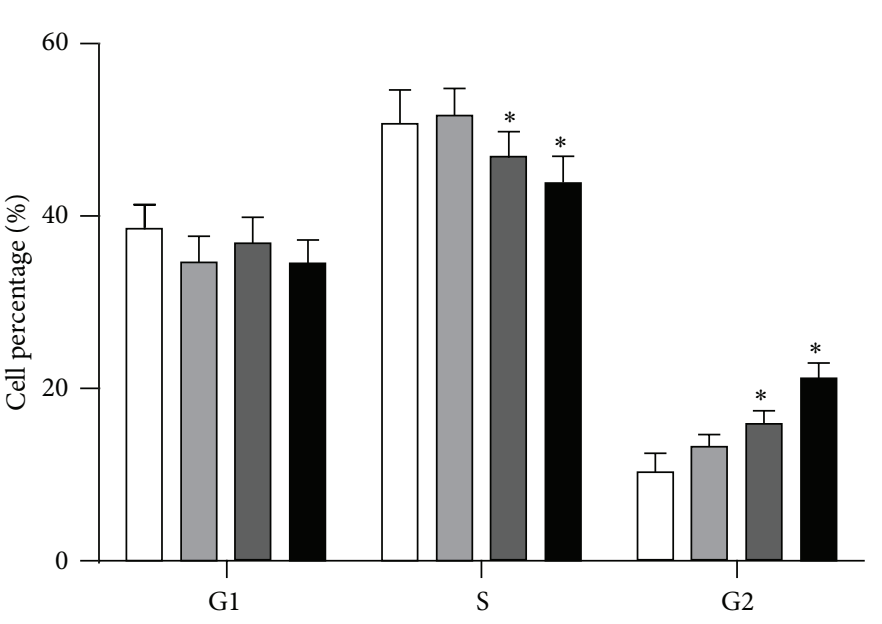

HG

$400 \mu \mathrm{mol} / \mathrm{L}$

(b)

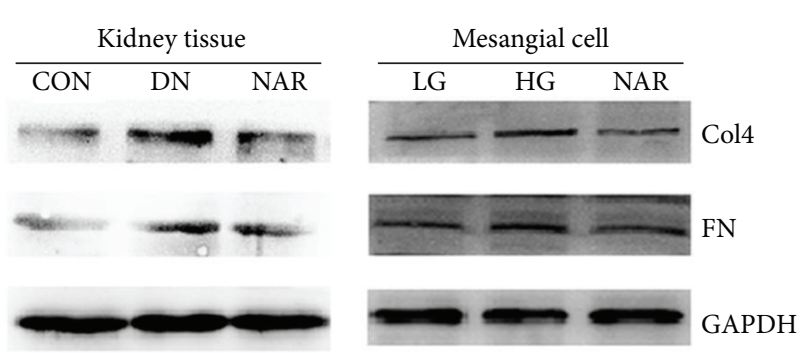

(d)
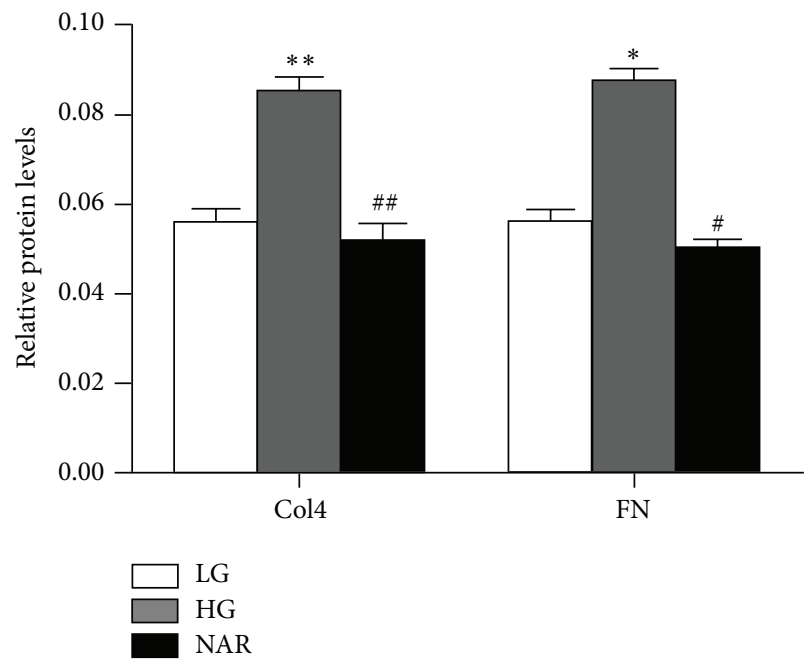

(f)

Figure 2: Continued. 

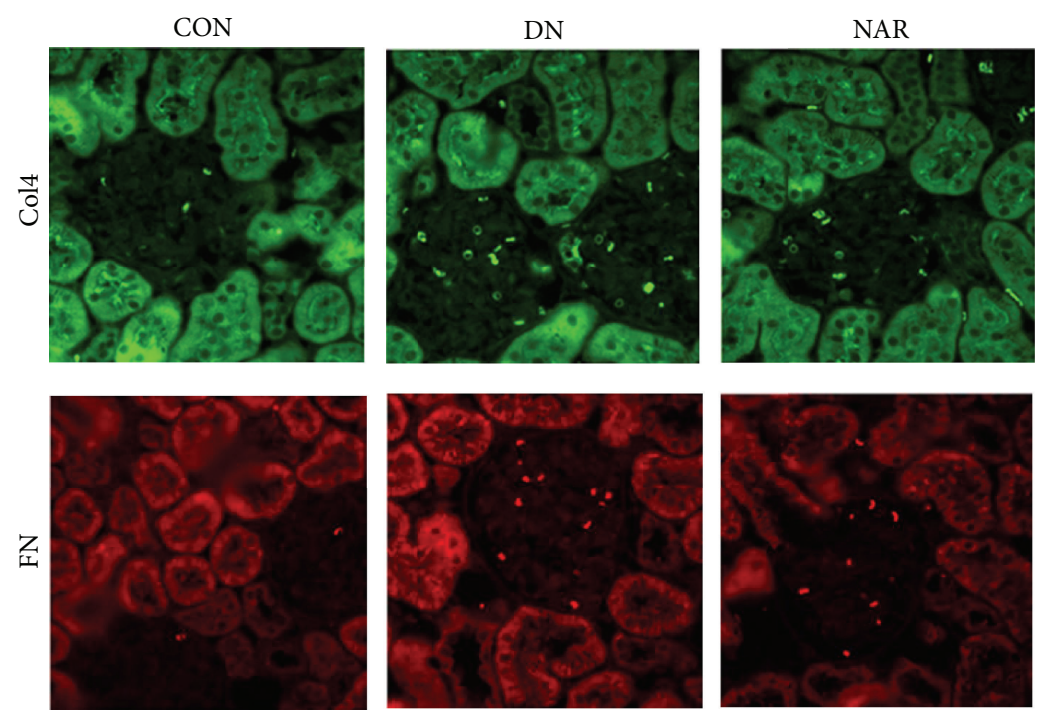

(g)
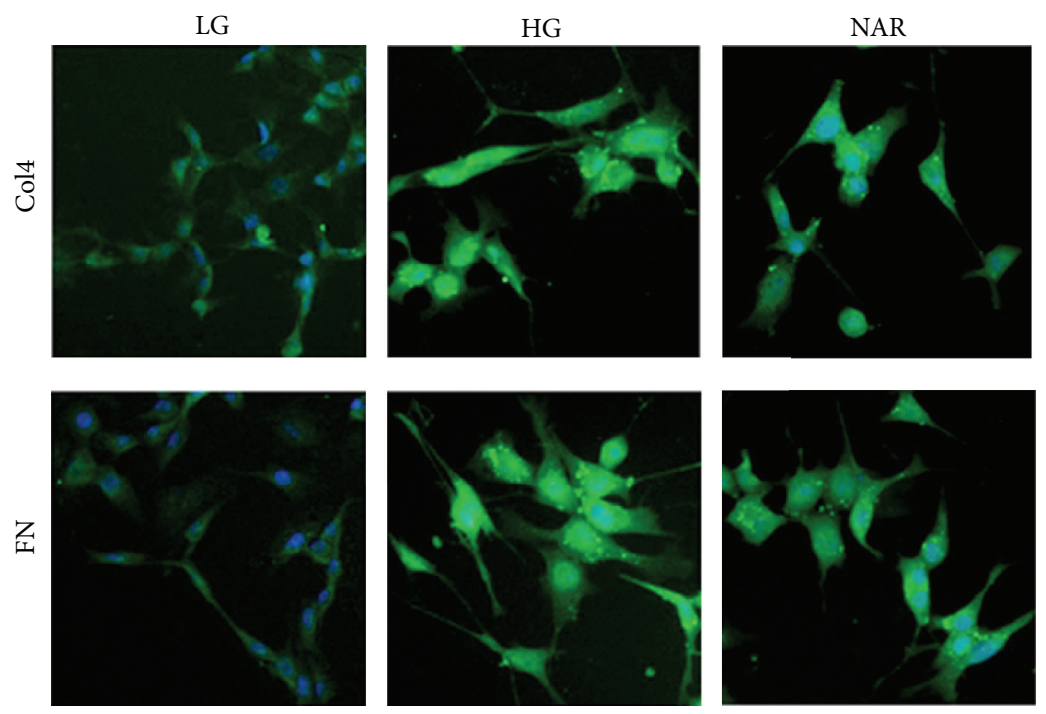

(h)

FIGURE 2: Effects of NAR on cell proliferation, cell cycle, and deposition of ECM proteins. (a) MTT analyses of cell proliferation rates. (b) Quantifications of the phases of the cell cycle analysis by flow cytometry. (c) Real-time RT PCR analyses of Col4 and FN mRNAs from kidney tissues. (d) Western blot analysis of Col4 and FN proteins in kidney tissues and MMCs. (e) Quantifications of the western blot bands of Col4 and FN expressions in DN rats. (f) Quantifications of the western blot bands of Col4 and FN expressions in MMCs. (g) Immunofluorescence of Col4 and FN proteins in kidney tissues of rats. (h) Immunofluorescence of Col4 and FN proteins in MMCs. (a, b) Results are expressed as mean \pm standard deviation ( $n=3$ per group). ${ }^{*} p<0.05 ;{ }^{* *} p<0.01$ versus HG group. (c) Results were normalized with GAPDH and expressed as mean \pm standard deviation $\left(n=4\right.$ per group). ${ }^{*} p<0.05$ versus CON group; ${ }^{\#} p<0.05$ versus DN group. (e) Results were normalized with GAPDH and expressed as mean \pm standard deviation $\left(n=3\right.$ per group). ${ }^{*} p<0.05 ;{ }^{* *} p<0.01$ versus CON group; ${ }^{\#} p<0.05$ versus DN group. (f) Results were normalized with GAPDH and expressed as mean \pm standard deviation ( $n=3$ per group). ${ }^{*} p<0.05 ;{ }^{* *} p<0.01$ versus LG group; ${ }^{\#} p<0.05 ;{ }^{\# \#} p<0.01$ versus HG group.

2(e), and 2(f)), and immunofluorescence (Figures 2(g) and 2(h)). The results showed that the mRNA and protein of Col4 and FN were remarkably increased in the DN or HG group compared with the CON or LG group and decreased when NAR was treated in mice and cells. Taken together, our results suggested that NAR could improve the excessive deposition of ECM.
3.3. Effect of NAR on Col4 and FN Expressions with Let-7a Intervention. Our previous study demonstrated that several miRNAs were differentially expressed in blood samples of DN patients by miRNA array and real-time PCR, including let7a, let-7d, let-7f, miR-363, and miR-4429 (data not shown). Furthermore, our result displayed that only let- $7 \mathrm{a}$ was reversed when treated with NAR among the five miRNAs in 


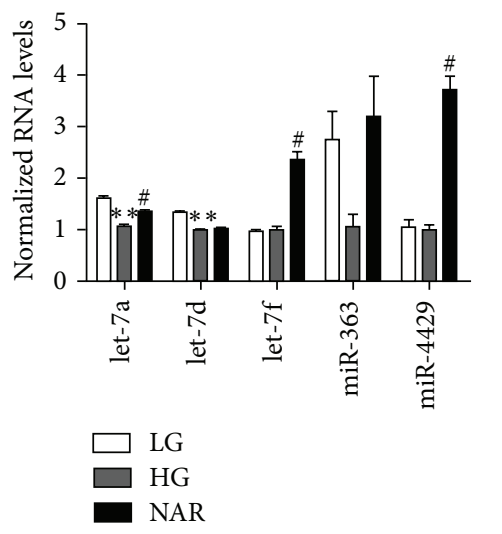

(a)

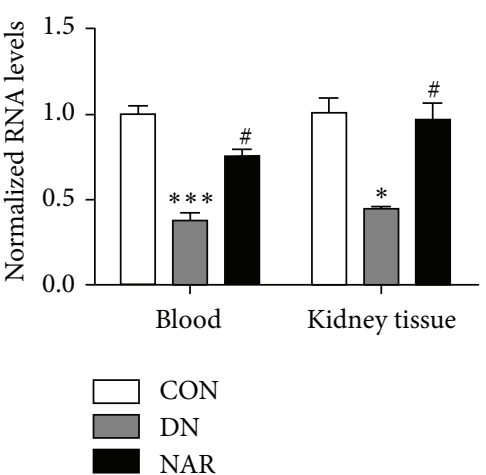

(b)

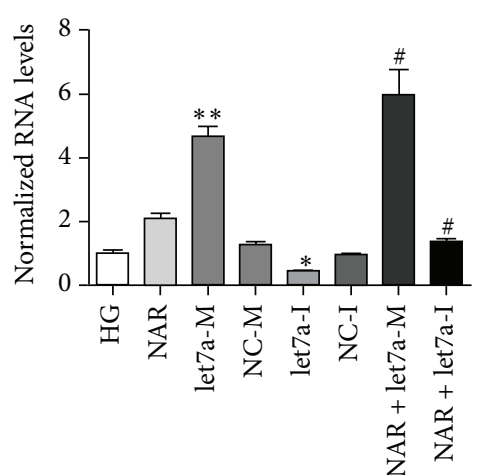

(c)

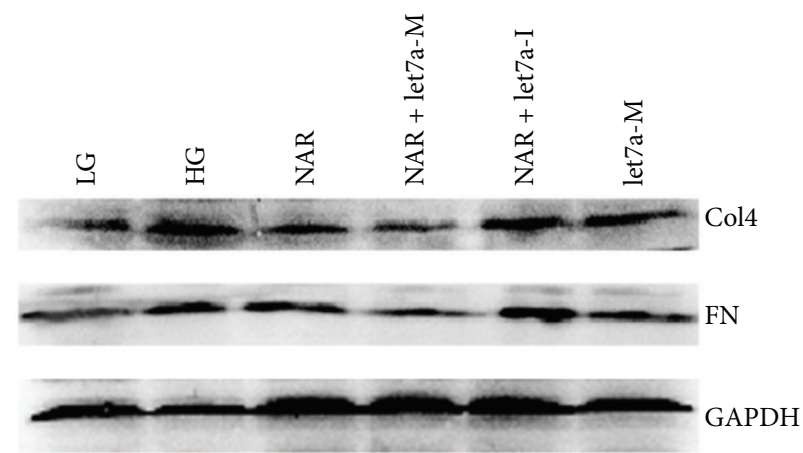

(d)

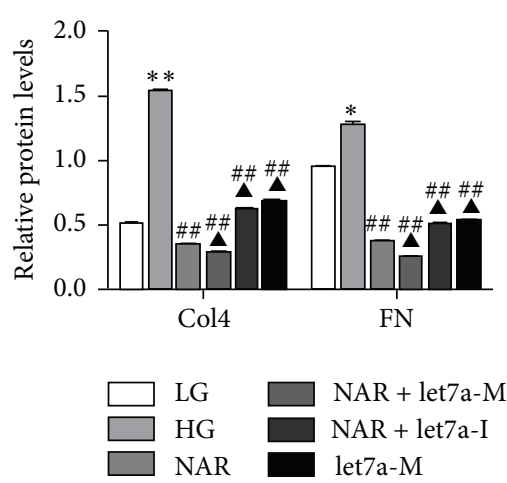

(e)

FIGURE 3: NAR inhibited deposition of ECM by upregulating let-7a expression. (a) MiRNAs expressions in MMCs treated with NAR. (b) Real-time RT PCR analysis of let-7a in blood and kidney tissues of rats. (c) Real-time RT PCR analysis of let-7a expressions. Data showed let-7a was upregulated or downregulated by let-7a mimics or let-7a inhibitor. Moreover, let-7a was increased in NAR group compared with HG untreated group. (d) Western blot analysis of Col4 and FN proteins in MMCs transferring let-7a mimics or inhibitor with NAR. (e) Quantifications of the western blot bands of Col4 and FN expressions in MMCs transferring let-7a mimics or inhibitor with NAR. (a) Results were normalized with U6 and expressed as mean \pm standard deviation ( $n=3$ per group). ${ }^{* *} p<0.01$ versus LG group; ${ }^{*} p<0.05$ versus HG group. (b) Results were normalized with U6 and expressed as mean \pm standard deviation $\left(n=4\right.$ per group). ${ }^{*} p<0.05 ;{ }^{*} p<0.05 ;^{* * *} p<0.001$ versus CON group; ${ }^{*} p<0.05$ versus DN group. (c) Results were normalized with U6 and expressed as mean \pm standard deviation $(n=3$ per group). ${ }^{*} p<0.05 ;{ }^{* *} p<0.01$ versus HG group; ${ }^{*} p<0.05$ versus NAR group. (e) Results were normalized with GAPDH and expressed as mean \pm standard deviation ( $n=3$ per group). ${ }^{* *} p<0.01$ versus LG group; ${ }^{\# \#} p<0.01$ versus HG group; ${ }^{\mathbf{A}} p<0.05$ versus NAR group.

mesangial cells with high glucose (Figure 3(a)). To determine whether NAR affected the expression of let-7a in vivo, let7 a expression was examined in blood and kidney tissue of $\mathrm{DN}$ rats. The results showed that let-7a was significantly decreased in the DN group compared with the CON group. After the treatment of NAR, the expression of let-7a was significantly enhanced in the NAR group compared with the DN group (Figure 3(b)). These results demonstrated that NAR upregulated let-7a expression both in vivo and in vitro in DN.

We further observed whether NAR affected fibrosis markers Col4 and FN expressions by regulating let-7a in cells. MMCs were transfected with let-7a mimics (let7a-M), let-7a inhibitor (let7a-I), NAR, or NAR with let-7a intervention. The results showed that let-7a was highly expressed in let-7a mimics group and decreased in inhibitor group. The expression of let-7a was significantly elevated in NAR + let-7a group, whereas let-7a declined in NAR + let-7a inhibitor group (Figure 3(c)). Moreover, the expressions of Col4 and FN were decreased in let-7a or NAR group compared with those in the untreated HG group. Interestingly, the expressions of Col4 and FN were lower after transferring let-7a mimic and NAR into mesangial cell compared with NAR or let7a group (Figures 3(d) and 3(e)). So our results suggested that NAR could improve the excessive deposition of ECM by upregulating let-7a expression.

3.4. Let-7a Negatively Regulated TGFBR1 Expression. To evaluate possible functions of let-7a, we screened potential target genes of let-7a. Firstly, according to bioinformatics software Targetscan (http://www.targetscan.org/), we found that DN related gene-TGFBR1 was a potential target of let-7a. By analyzing homology, we found that the putative mmu-let7a target site in TGFBR1 $3^{\prime}$-UTR was highly conserved in 


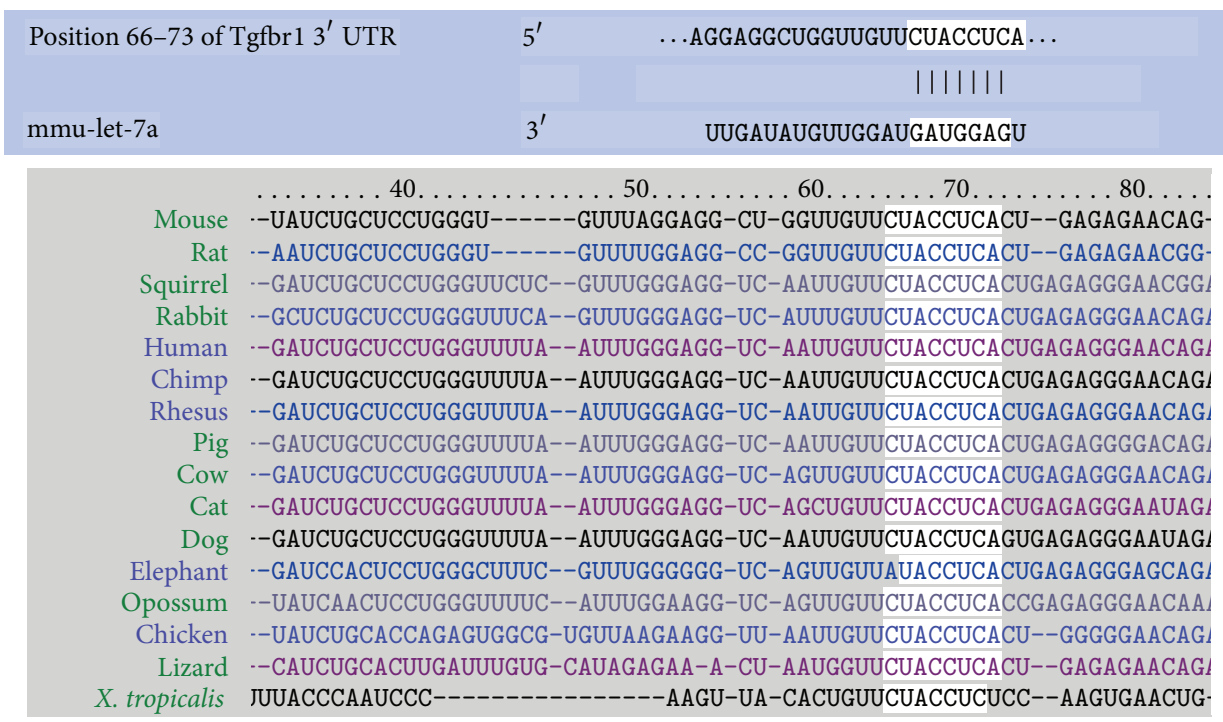

(a)

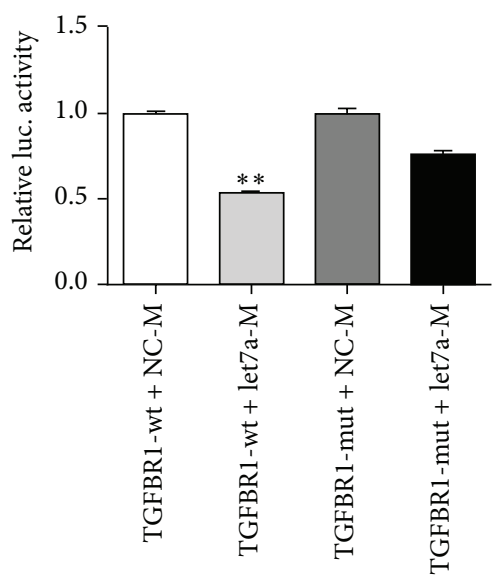

(b)

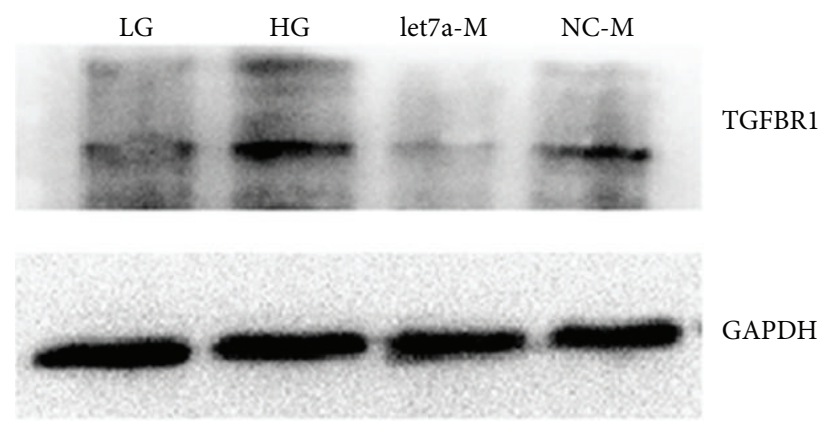

(c)

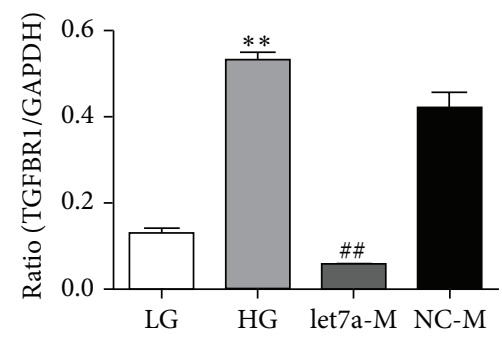

(d)

FIGURE 4: TGFBR1 was a target for let-7a. (a) Let-7a binding region of the $3^{\prime}$-UTR of TGFBR1 from fifteen species. Paired bases were exhibited by a black line. And the binding site was boxed with a black rectangle. (b) Luciferase activity of reporters in the presence or absence of let7a mimics in 293T cells. Luc activity was significantly decreased in TGFBR1-wt+let7a-M. (c) Let-7a negatively regulated the expression of TGFBR1 in MMCs by western blot. (d) Quantifications of the western blot bands. (b) Data shown as mean \pm standard deviation ( $n=3$ per group). ${ }^{* *} p<0.01$ versus TGFBR1-wt+NC-M group. (d) Results were normalized with GAPDH and expressed as mean \pm standard deviation ( $n=3$ per group). ${ }^{* *} p<0.01$ versus LG group; ${ }^{\# \#} p<0.01$ versus HG group.

sixteen genomes (Figure 4(a)). Secondly, we performed the dual-luciferase reporter assay and western blot. Transcripts carrying the TGFBR1 $3^{\prime}$-UTR-wt exhibited a significant reduction in luciferase activity in the presence of let-7a. In contrast, the mimics negative control had no significant effect on the luciferase activity (Figure 4(b)). Meanwhile, western blot results showed that the expression level of TGFBR1 protein was reduced significantly in the let-7a mimics group 
compared with the HG group (Figures 4(c) and 4(d)). The data indicated that let-7a could negatively regulated TGFBR1 expression. Therefore, TGFBR1 was a target for let-7a.

3.5. Effect of NAR on TGF- $\beta 1 /$ Smads Signaling with Let$7 a$ Intervention. TGF- $\beta 1$ is recognized as a major mediator of renal fibrosis because it is able to stimulate the accumulation of ECM protein and TGF- $\beta 1 /$ smad signaling activation involving in this process [29]. To determine that whether NAR affected the TGF- $\beta 1 /$ smad signaling in vivo, we examined TGF- $\beta 1$, TGFBR1, smad2, and smad7 mRNA and protein expressions in kidney tissue of DN rats. The results of real-time RT PCR showed that TGF- $\beta 1$, TGFBR1, and smad 2 mRNAs were remarkably increased in the DN group compared with the CON group, while smad7 mRNA was declined. NAR reduced the expressions of TGF- $\beta 1$, TGFBR1, and smad2 and increased smad7 mRNAs (Figure 5(a)). Meanwhile, the western blot results showed that TGF- $\beta 1 /$ smad signaling was highly activated in DN group as revealed by a marked upregulation of TGF- $\beta 1$, TGFBR1, and $\mathrm{p}-\mathrm{smad} 2 / \mathrm{smad} 2$ and downexpression of smad7, whereas NAR directly reduced TGF- $\beta 1$, TGFBR 1 , and $\mathrm{p}-\mathrm{smad} 2 / \operatorname{smad} 2$ and increased smad7 protein expression (Figures 5(b) and $5(c))$. We further observed the effects of NAR on TGF$\beta 1$, TGFBR1, smad2/p-smad2, and smad7 protein in MMCs. We found that the expressions of TGF- $\beta 1$, TGFBR1, and smad $2 / \mathrm{p}$-smad 2 significantly decreased and smad 7 increased in NAR group compared with those in HG group (Figures 5(b) and 5(d)). The results of immunofluorescence for TGF$\beta 1$ and TGFBR1 were consistent with the results of western blot (Figure 5(e)). Together, our results suggested that TGF$\beta 1 /$ smad signaling was activated in DN rats and MMCs in high glucose condition and NAR could inhibit TGF- $\beta 1 / \mathrm{smad}$ signaling activation in vivo and vitro.

Furthermore, we observed whether NAR affected TGF$\beta 1 /$ smad signaling by regulating let-7a in MMCs or not. We found that overexpression of let-7a and NAR treatment decreased the ratio of $\mathrm{p}$-smad2/smad2 and TGFBR1 proteins compared with MMCs without treatment. Additionally, NAR alleviated the change in the ratio of $\mathrm{p}-\mathrm{smad} 2 / \mathrm{smad} 2$ and TGFBR1 proteins cooperation with let7a-M more significantly than NAR group and let7a-M group, whereas the ratio of $\mathrm{p}$-smad2/smad 2 and TGFBR1 protein was increased in the NAR + let-7a inhibitor group compared with NAR group (Figures 5(f) and 5(g)). Our results suggested that TGF$\beta 1 /$ smads signaling was activated in DN rats and MMCs in high glucose condition and NAR inhibited TGF- $\beta 1 /$ smads signaling activation through upregulating let-7a and suppressing TGFBR1 expression.

\section{Discussion}

DN is one of the most important diabetic microvascular complications. The mesangial cell proliferation plays an important role in DN. Glomerular mesangial cell acts actively in glomeruli, which can secrete ECM and produce cytokine, phagocyte, and clear macromolecules, and it has systolic function like smooth muscle cell. Studies have confirmed that mesangial cell was the important glomerular resident cells in the synthesis of ECM proteins [30,31]. Deposition of excessive ECM molecules, predominant collagens, and fibronectin in the kidney will lead to kidney hyperplasia and glomerular area enlargement, which adversely affected the structure and function of the kidney. However, the underlying mechanism is not completely understood.

NAR is a natural flavonoid commonly occurring in many plant foods. It played an important role in diabetes and its complications [32]. Researches revealed that NAR could affect dyslipidemia, apoB overproduction, and hyperinsulinemia in LDL-receptor null mice with diet-induced insulin resistance [33]. NAR could play antihyperglycemic and antioxidative roles in diabetic rats [34]. And the antidiabetic effect of NAR might be insulin-like effect in type 2 diabetic rats [35]. Additionally, it was reported that NAR supplement increased its deposit in the liver and kidney of diabetic mice, and plasma levels of glucose and blood urea nitrogen were both decreased in NAR group, while insulin level and creatinine clearance were increased in NAR group compared with the diabetic control group [16]. In this study, our results showed NAR could not only decrease the blood glucose, $24 \mathrm{~h}$ urinary protein, kidney index, and glomerular area but also increase Ccr in DN rats. Also, we examined the therapeutic effects of NAR in DN rats and mesangial cells under diabetic condition. Our data showed that NAR inhibited mesangial cells proliferation by delaying cell cycle at G2 phase. Moreover, Col4 and FN were highly expressed in DN rats and MMCs under high glucose condition, while NAR directly reduced the expressions of Col 4 and FN mRNA and proteins. Therefore, these findings displayed that NAR might participant in the development and progress of DN and suggested that NAR could play an important role in DN. However, the exact mechanism of NAR in DN is still unclear.

To explore the underlying mechanism of NAR in DN, several DN related miRNAs were focused on. Results showed let-7a was the only miRNA which reversed the expression level when treated with NAR in mesangial cells cultured with high glucose. Furthermore, numerous researches showed that let-7a was closely linked to modulate cell proliferation in various diseases [36-38]. Also, our previous studies also showed that the promoter hypermethylation and single nucleotide polymorphism of let-7a played important roles in DN $[21,22]$. Therefore, these studies suggested that let$7 \mathrm{a}$ might be related to the therapeutic effects of NAR in DN. In our study, real-time RT PCR results exhibited that let-7a expression was significantly decreased in both blood and kidney tissues of DN rats and mesangial cells under hyperglycemic condition. And the expression of let-7a was elevated after NAR treatment in vivo and in vitro. These data suggested that NAR could upregulate the expression of let-7a in DN. Additionally, NAR alleviated the changes of Col4 and FN proteins cooperated with let7a mimics more significantly than NAR group, whereas the inhibitory effect of NAR cooperated with let-7a inhibitor was weakened. So these results suggested that NAR alleviated the deposition of ECM proteins by upregulating let-7a expression.

In the famous DN related pathway-TGF- $\beta 1 /$ smad signaling pathway, the binding of TGF- $\beta 1$ toTGFBR1 could activate 


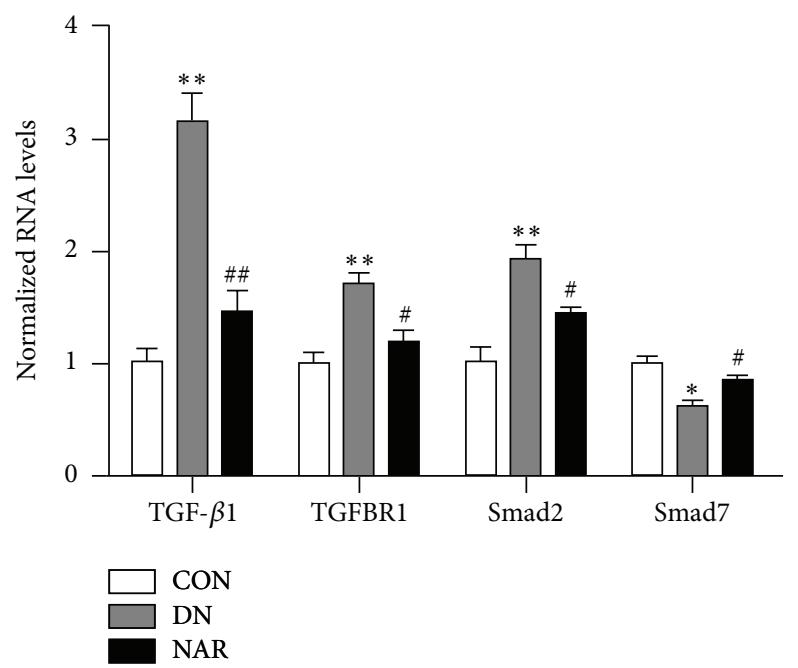

(a)
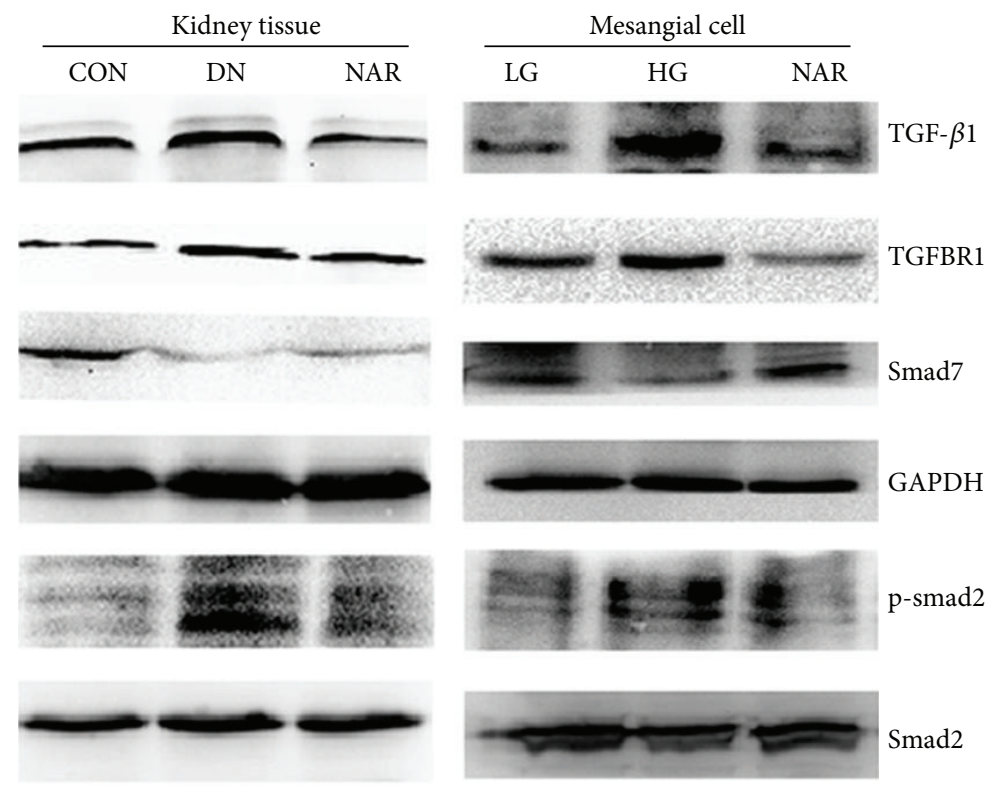

(b)
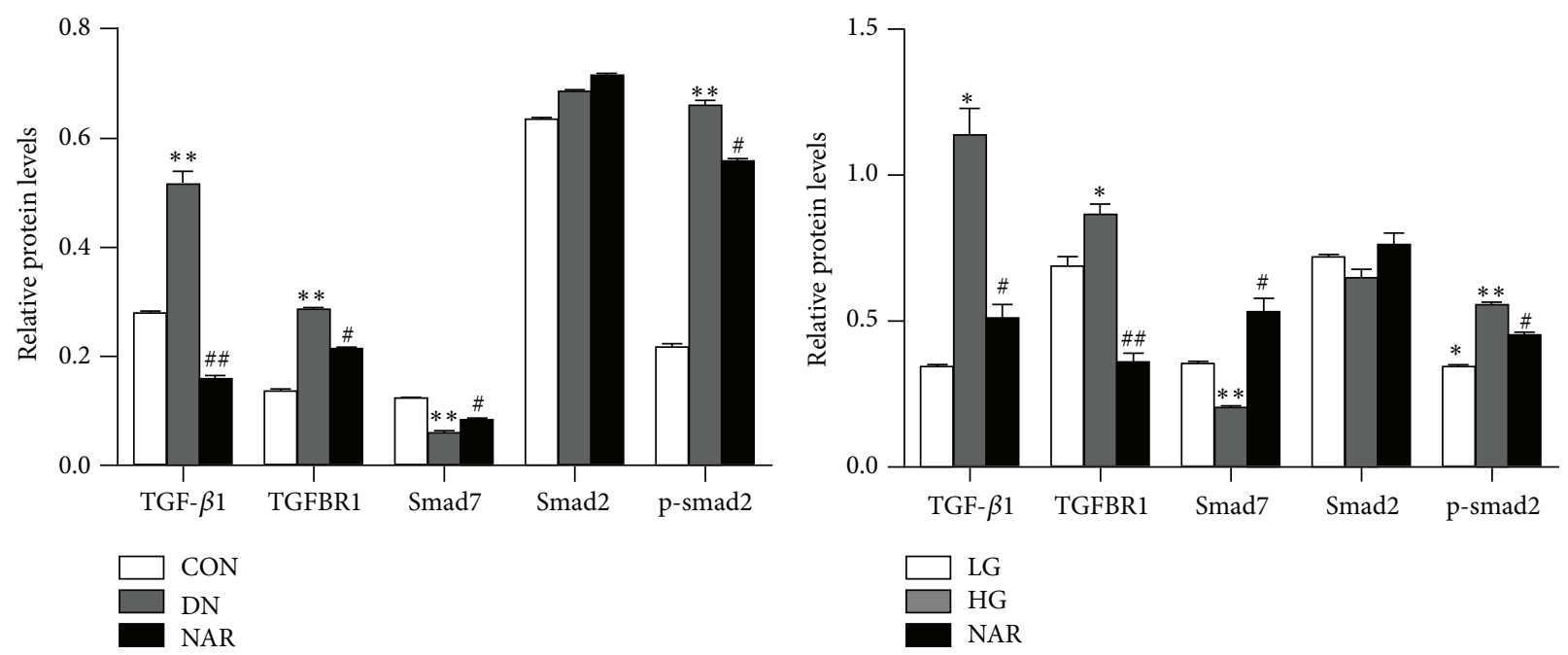

(c)

(d)

Figure 5: Continued. 

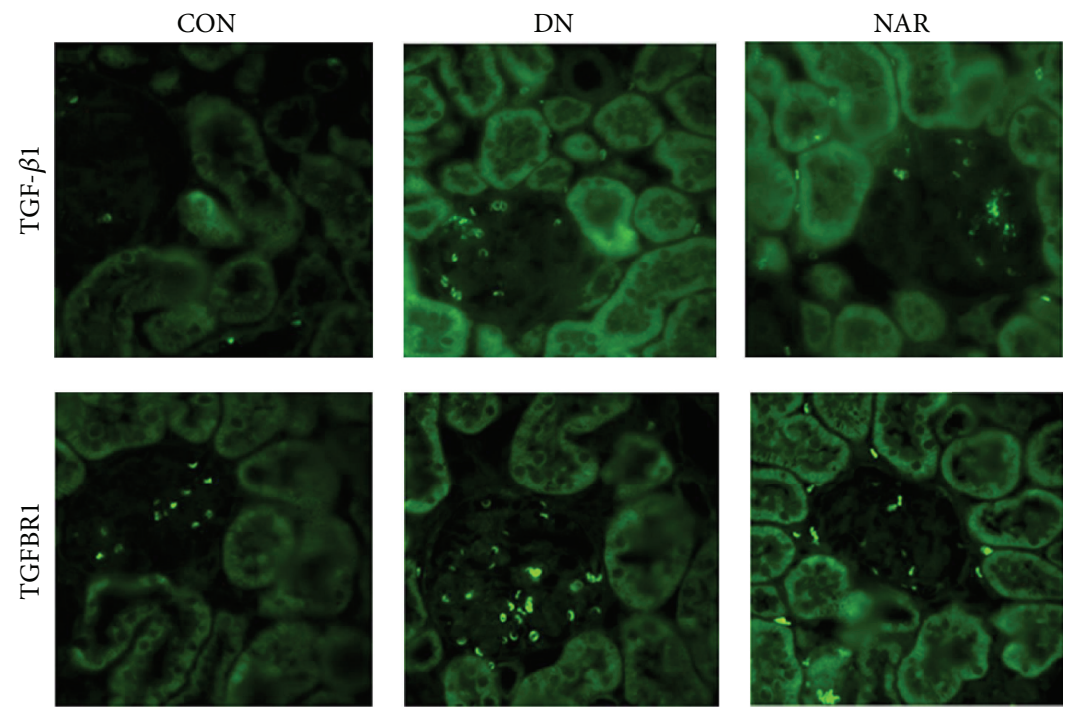

(e)
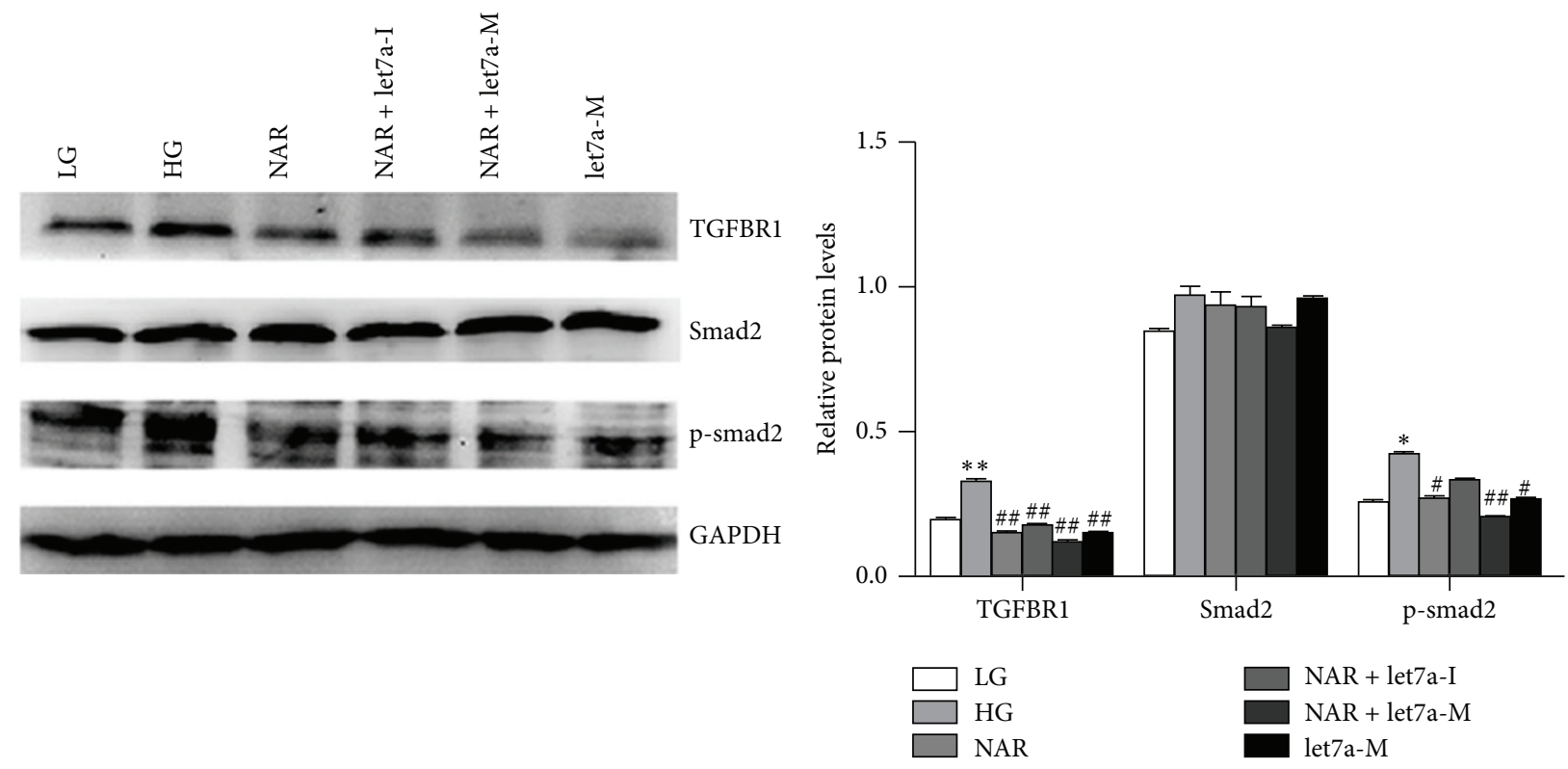

(f)

(g)

FIGURE 5: NAR inhibited TGF- $\beta 1$ /smads signaling through let-7a in vivo and in vitro. (a) Real-time RT PCR showed the mRNA levels of TGF$\beta 1$, TGFBR1, smad2, and smad7 of kidney tissues in rats. (b) Western blot analysis of TGF- $\beta 1$, TGFBR1, smad2, p-smad2, and smad7 proteins in kidney tissues and MMCs. (c) Quantifications of the western blot bands of TGF- $\beta 1$, TGFBR1, smad7, and p-smad 2 expressions in DN rats. (d) Quantifications of the western blot bands of TGF- $\beta 1$, TGFBR1, smad7, and p-smad2 expressions in MMCs. (e) Immunofluorescence of TGF- $\beta 1$ and TGFBR1 proteins in kidney tissues of rats. (f) Western blot analysis of TGFBR1, smad2, and p-smad2 proteins in MMCs transferring let-7a mimics or inhibitor with NAR. (g) Quantifications of the western blot bands of TGFBR1 and p-smad2 expressions in MMCs transferring let-7a mimics or inhibitor with NAR. (a) Results were normalized with GAPDH and expressed as mean \pm standard deviation $\left(n=4\right.$ per group). ${ }^{*} p<0.05 ;{ }^{* *} p<0.05$ versus CON group; ${ }^{\#} p<0.05 ;{ }^{\# \#} p<0.01$ versus DN group. (c) Results were normalized with GAPDH and expressed as mean \pm standard deviation $\left(n=3\right.$ per group). ${ }^{* *} p<0.01$ versus CON group; ${ }^{\#} p<0.05 ;{ }^{\# \#} p<0.01$ versus DN group. (d) Results were normalized with GAPDH and expressed as mean \pm standard deviation ( $n=3$ per group). ${ }^{*} p<0.05 ;{ }^{* *} p<0.01$ versus LG group; ${ }^{\#} p<0.05 ;{ }^{\# \#} p<0.01$ versus HG group. (g) Results were normalized with GAPDH and expressed as mean \pm standard deviation ( $n=3$ per group). ${ }^{*} p<0.05 ;{ }^{* *} p<0.01$ versus LG group; ${ }^{\#} p<0.05$; ${ }^{\# \#} p<0.01$ versus HG group. 
phosphorylation of smad2 and smad3. Subsequently, phosphorylated smad 2 and $\operatorname{smad} 3$ bound to the common smad 4 and formed the smad complex to regulate the downstream gene transcription. In this process, smad7 could block the activation of TGF- $\beta 1 /$ smad signaling as an inhibitory factor [39]. Therefore, TGFBR1, TGF- $\beta 1$, and smads were key factors in the TGF- $\beta 1 /$ smad signaling pathway. Research showed NAR decreased cell invasion and metastasis by inhibition of TGF- $\beta 1 /$ smads signaling pathway in pancreatic cancer, and NAR also reduced TGF- $\beta 1$-induced hepatic satellite cell extracellular matrix deposition by inhibiting TGF- $\beta 1 /$ smads signals $[12,40]$. In this study, our data displayed that there was a significant reduction of TGFBR1 protein in the presence of let-7a mimics by dual-luciferase reporter assay, and overexpression of let-7a could decrease the expression of TGFBR1 protein by western blot. These data verified that TGFBR1 was a target for let-7a.

Our results showed that TGF- $\beta 1 /$ smads signaling was highly activated in DN rats and MMCs under high glucose condition, whereas NAR directly suppressed activation of TGF- $\beta 1 /$ smad signaling. More importantly, in vitro experiments, overexpression of let-7a decreased the expression of $\mathrm{p}$ smad 2 and TGFBR1 proteins compared with HG group and it suggested that let-7a may negatively regulate TGF- $\beta 1 /$ smads signaling by targeting TGFBR1. Meanwhile, NAR cooperated with let7a mimics; its effects were more remarkable than NAR or let-7a mimics' individual effect in the reductions of $\mathrm{p}$-smad2 and TGFBR1 proteins, while the reductions of $\mathrm{p}$ smad 2 and TGFBR1 proteins in the NAR cooperated with let-7a inhibitor group were weakened. Taken together, our data exhibited that NAR regulated the alteration of TGF$\beta 1 /$ smads signaling through upregulating let-7a expression and suppressing TGFBR1.

In summary, our study suggested that NAR ameliorated kidney injury and inhibited mesangial cells proliferation and accumulation of ECM in DN. NAR played a biological role in TGF- $\beta 1 /$ smad signaling pathway by regulating let7a/TGFBR1, and let-7a might be a novel therapeutic target for NAR protect against DN.

\section{Competing Interests}

The authors declare no competing interests.

\section{Acknowledgments}

This work was supported by the National Natural Science Foundations of China (nos. 81270912 and 81570747), Chongqing Science and Technology Commissions (cstc2013jcyjA10044 and cstc2015jcyjA10026), and the College Students Innovation Project of Chongqing Medical University.

\section{References}

[1] K. Sharma and F. N. Ziyadeh, "Hyperglycemia and diabetic kidney disease. The case for transforming growth factor- $\beta$ as a key mediator," Diabetes, vol. 44, no. 10, pp. 1139-1146, 1995.
[2] J. M. Forbes, M. T. Coughlan, and M. E. Cooper, "Oxidative stress as a major culprit in kidney disease in diabetes," Diabetes, vol. 57, no. 6, pp. 1446-1454, 2008.

[3] D. W. Piotrowski, "Mineralocorticoid receptor antagonists for the treatment of hypertension and diabetic nephropathy," Journal of Medicinal Chemistry, vol. 55, no. 18, pp. 7957-7966, 2012.

[4] J. Wada and H. Makino, "Inflammation and the pathogenesis of diabetic nephropathy," Clinical Science, vol. 124, no. 3, pp. 139152,2013

[5] S. S. Al-Rejaie, A. M. Aleisa, H. M. Abuohashish et al., "Naringenin neutralises oxidative stress and nerve growth factor discrepancy in experimental diabetic neuropathy," Neurological Research, vol. 37, no. 10, pp. 924-933, 2015.

[6] R. Banjerdpongchai, B. Wudtiwai, P. Khaw-on, W. Rachakhom, N. Duangnil, and P. Kongtawelert, "Hesperidin from Citrus seed induces human hepatocellular carcinoma HepG2 cell apoptosis via both mitochondrial and death receptor pathways," Tumor Biology, vol. 37, no. 1, pp. 227-237, 2016.

[7] R. M. Martinez, F. A. Pinho-Ribeiro, V. S. Steffen et al., "Naringenin inhibits UVB irradiation-induced inflammation and oxidative stress in the skin of hairless mice," Journal of Natural Products, vol. 78, no. 7, pp. 1647-1655, 2015.

[8] I. E. Orhan, S. F. Nabavi, M. Daglia, G. C. Tenore, K. Mansouri, and S. M. Nabavi, "Naringenin and atherosclerosis: a review of literature," Current Pharmaceutical Biotechnology, vol. 16, no. 3, pp. 245-251, 2015.

[9] L. N. Bodduluru, E. R. Kasala, R. M. Madhana et al., "Naringenin ameliorates inflammation and cell proliferation in benzo(a)pyrene induced pulmonary carcinogenesis by modulating CYP1A1, NFkB and PCNA expression," International Immunopharmacology, vol. 30, pp. 102-110, 2016.

[10] H. M. Song, G. H. Park, H. J. Eo et al., "Anti-proliferative effect of naringenin through p38-dependent downregulation of cyclin D1 in human colorectal cancer cells," Biomolecules and Therapeutics, vol. 23, no. 4, pp. 339-344, 2015.

[11] R.-F. Li, Y.-Q. Feng, J.-H. Chen, L.-T. Ge, S.-Y. Xiao, and X.L. Zuo, "Naringenin suppresses K562 human leukemia cell proliferation and ameliorates Adriamycin-induced oxidative damage in polymorphonuclear leukocytes," Experimental and Therapeutic Medicine, vol. 9, no. 3, pp. 697-706, 2015.

[12] X. Liu, W. Wang, H. Hu et al., "Smad3 specific inhibitor, naringenin, decreases the expression of extracellular matrix induced by TGF- $\beta 1$ in cultured rat hepatic stellate cells," Pharmaceutical Research, vol. 23, no. 1, pp. 82-89, 2006.

[13] J. C. Sánchez-Salgado, R. R. Ortiz-Andrade, F. Aguirre-Crespo et al., "Hypoglycemic, vasorelaxant and hepatoprotective effects of Cochlospermum vitifolium (Willd.) Sprengel: a potential agent for the treatment of metabolic syndrome," Journal of Ethnopharmacology, vol. 109, no. 3, pp. 400-405, 2007.

[14] D. H. Priscilla, D. Roy, A. Suresh, V. Kumar, and K. Thirumurugan, "Naringenin inhibits $\alpha$-glucosidase activity: a promising strategy for the regulation of postprandial hyperglycemia in high fat diet fed streptozotocin induced diabetic rats," ChemicoBiological Interactions, vol. 210, no. 1, pp. 77-85, 2014.

[15] H. Yoshida, H. Watanabe, A. Ishida et al., "Naringenin suppresses macrophage infiltration into adipose tissue in an early phase of high-fat diet-induced obesity," Biochemical and Biophysical Research Communications, vol. 454, no. 1, pp. 95-101, 2014.

[16] S.-J. Tsai, C.-S. Huang, M.-C. Mong, W.-Y. Kam, H.-Y. Huang, and M.-C. Yin, "Anti-inflammatory and antifibrotic effects of 
naringenin in diabetic mice," Journal of Agricultural and Food Chemistry, vol. 60, no. 1, pp. 514-521, 2012.

[17] R. J. A. Frost and E. N. Olson, "Control of glucose homeostasis and insulin sensitivity by the Let-7 family of microRNAs," Proceedings of the National Academy of Sciences of the United States of America, vol. 108, no. 52, pp. 21075-21080, 2011.

[18] H. Zhu, N. Shyh-Chang, A. V. Segr et al., "The Lin28/let-7 axis regulates glucose metabolism," Cell, vol. 147, no. 1, pp. 81-94, 2011.

[19] L. Q. Jiang, N. Franck, B. Egan et al., "Autocrine role of interleukin-13 on skeletal muscle glucose metabolism in type 2 diabetic patients involves microRNA let-7," The American Journal of Physiology -Endocrinology and Metabolism, vol. 305, no. 11, pp. E1359-E1366, 2013.

[20] J. T. Park, M. Kato, L. Lanting et al., "Repression of let-7 by transforming growth factor- $\beta 1$-induced Lin 28 upregulates collagen expression in glomerular mesangial cells under diabetic conditions," American Journal of Physiology-Renal Physiology, vol. 307, no. 12, pp. F1390-F1403, 2014.

[21] R. Peng, H. Liu, H. Peng et al., "Promoter hypermethylation of let-7a-3 is relevant to its down-expression in diabetic nephropathy by targeting UHRF1," Gene, vol. 570, no. 1, pp. 57-63, 2015.

[22] J. Zhou, R. Peng, T. Li et al., "A potentially functional polymorphism in the regulatory region of let-7a-2 is associated with an increased risk for diabetic nephropathy," Gene, vol. 527, no. 2, pp. 456-461, 2013.

[23] S. Dangi-Garimella, M. J. Strouch, P. J. Grippo, D. J. Bentrem, and H. G. Munshi, "Collagen regulation of let-7 in pancreatic cancer involves TGF- $\beta 1$-mediated membrane type 1-matrix metalloproteinase expression," Oncogene, vol. 30, no. 8, pp. 1002-1008, 2011.

[24] Y. Liu, H. Li, J. Feng et al., "Lin28 induces epithelial-tomesenchymal transition and stemness via downregulation of let-7a in breast cancer cells," PLoS ONE, vol. 8, article e83083, 2013.

[25] K. Makino, M. Jinnin, A. Hirano et al., "The downregulation of microRNA let-7a contributes to the excessive expression of type I collagen in systemic and localized scleroderma," Journal of Immunology, vol. 190, no. 8, pp. 3905-3915, 2013.

[26] K. Srinivasan, B. Viswanad, L. Asrat, C. L. Kaul, and P. Ramarao, "Combination of high-fat diet-fed and low-dose streptozotocintreated rat: a model for type 2 diabetes and pharmacological screening," Pharmacological Research, vol. 52, no. 4, pp. 313-320, 2005.

[27] T. T. Zhao, H. J. Zhang, X. G. Lu et al., "Chaihuang-Yishen granule inhibits diabetic kidney disease in rats through blocking TGF- $\beta$ /Smad3 signaling," PLoS ONE, vol. 9, article e90807, 2014.

[28] T. Yokozawa, T. Nakagawa, K. Wakaki, and F. Koizumi, "Animal model of diabetic nephropathy," Experimental and Toxicologic Pathology, vol. 53, no. 5, pp. 359-363, 2001.

[29] H. Y. Lan, “Transforming growth factor- $\beta /$ Smad signalling in diabetic nephropathy," Clinical and Experimental Pharmacology \& Physiology, vol. 39, no. 8, pp. 731-738, 2012.

[30] A. Nerlich and E. Schleicher, "Immunohistochemical localization of extracellular matrix components in human diabetic glomerular lesions," The American Journal of Pathology, vol. 139, no. 4, pp. 889-899, 1991.

[31] J. Floege, R. J. Johnson, K. Gordon et al., "Increased synthesis of extracellular matrix in mesangial proliferative nephritis," Kidney International, vol. 40, no. 3, pp. 477-488, 1991.
[32] J. Chen, S. Mangelinckx, A. Adams, Z.-T. Wang, W.-L. Li, and N. De Kimpe, "Natural flavonoids as potential herbal medication for the treatment of diabetes mellitus and its complications," Natural Product Communications, vol. 10, no. 1, pp. 187-200, 2015.

[33] E. E. Mulvihill, E. M. Allister, B. G. Sutherland et al., "Naringenin prevents dyslipidemia, apolipoprotein B overproduction, and hyperinsulinemia in LDL receptor-null mice with dietinduced insulin resistance," Diabetes, vol. 58, no. 10, pp. 21982210, 2009.

[34] T. Annadurai, A. R. Muralidharan, T. Joseph, M. J. Hsu, P. A. Thomas, and P. Geraldine, "Antihyperglycemic and antioxidant effects of a flavanone, naringenin, in streptozotocinnicotinamide-induced experimental diabetic rats," Journal of Physiology and Biochemistry, vol. 68, no. 3, pp. 307-318, 2012.

[35] R. R. Ortiz-Andrade, J. C. Sánchez-Salgado, G. NavarreteVázquez et al., "Antidiabetic and toxicological evaluations of naringenin in normoglycaemic and NIDDM rat models and its implications on extra-pancreatic glucose regulation," Diabetes, Obesity \& Metabolism, vol. 10, no. 11, pp. 1097-1104, 2008.

[36] R. Tang, C. Yang, X. Ma et al., "MiR-let-7a inhibits cell proliferation, migration, and invasion by down-regulating PKM2 in gastric cancer," Oncotarget, vol. 7, no. 5, pp. 5972-5984, 2016.

[37] Y. Li, X. Zhang, D. Chen, and C. Ma, "Let-7a suppresses glioma cell proliferation and invasion through TGF- $\beta / \mathrm{Smad} 3$ signaling pathway by targeting HMGA2," Tumor Biology, vol. 37, no. 6, pp. 8107-8119, 2016.

[38] X.-Y. He, J.-X. Chen, X. Ou-Yang, Z. Zhang, and H.-M. Peng, "Construction of let-7a expression plasmid and its inhibitory effect on k-Ras protein in A549 lung cancer cells," Journal of Southern Medical University, vol. 30, no. 11, pp. 2427-2431, 2010.

[39] H. Y. Chen, X. R. Huang, W. Wang et al., "The protective role of Smad7 in diabetic kidney disease: mechanism and therapeutic potential," Diabetes, vol. 60, no. 2, pp. 590-601, 2011.

[40] C. Lou, F. Zhang, M. Yang et al., "Naringenin decreases invasiveness and metastasis by inhibiting TGF- $\beta$-induced epithelial to mesenchymal transition in pancreatic cancer cells," PLOS ONE, vol. 7, article e50956, 2012. 


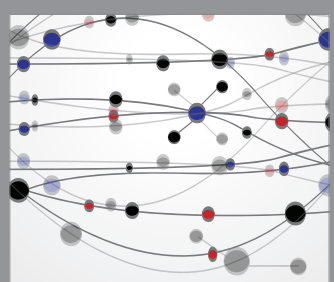

The Scientific World Journal
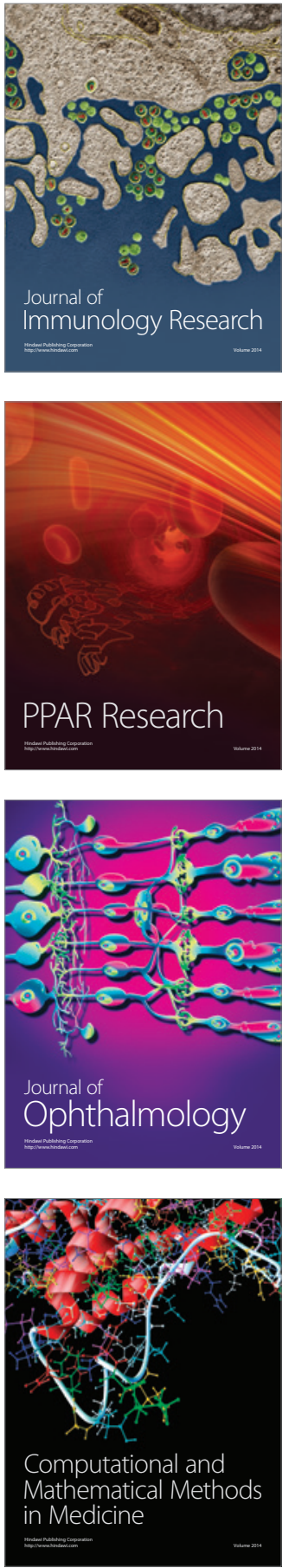

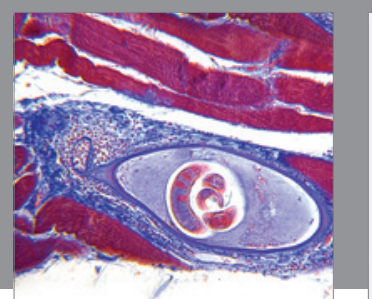

Gastroenterology Research and Practice

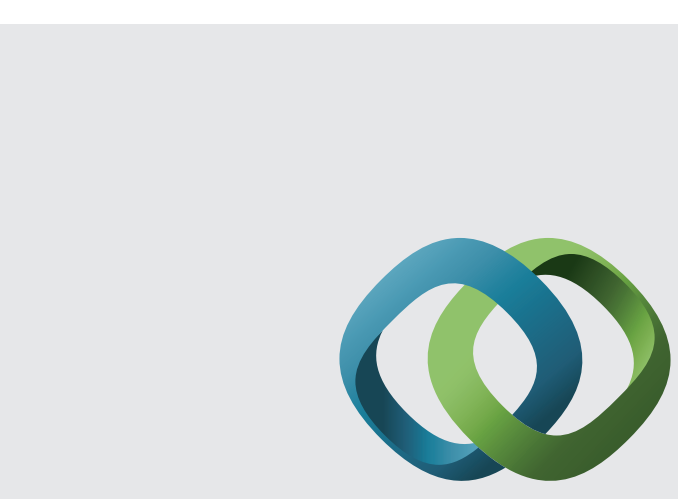

\section{Hindawi}

Submit your manuscripts at

http://www.hindawi.com
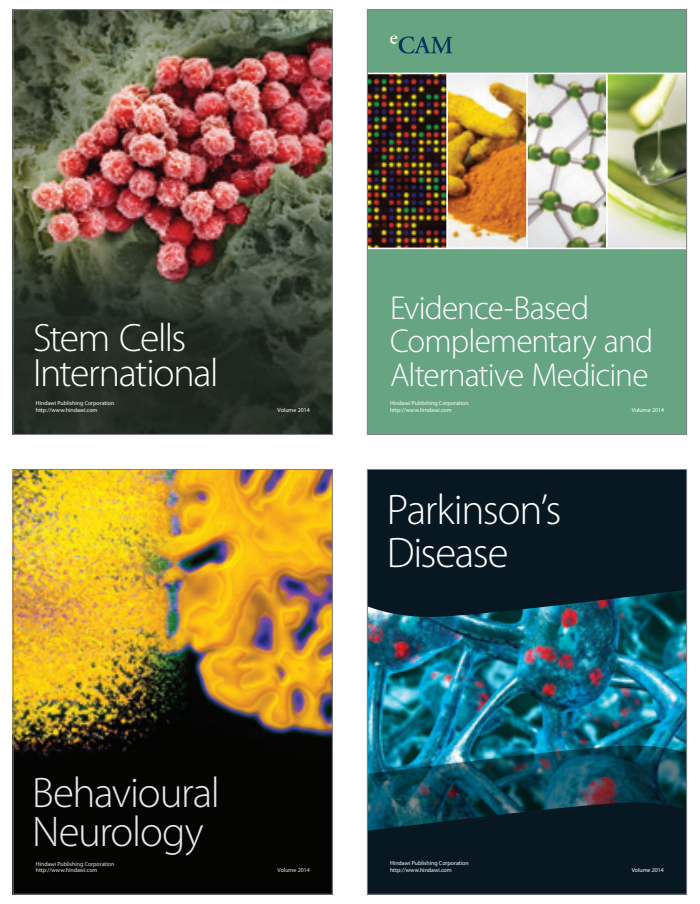
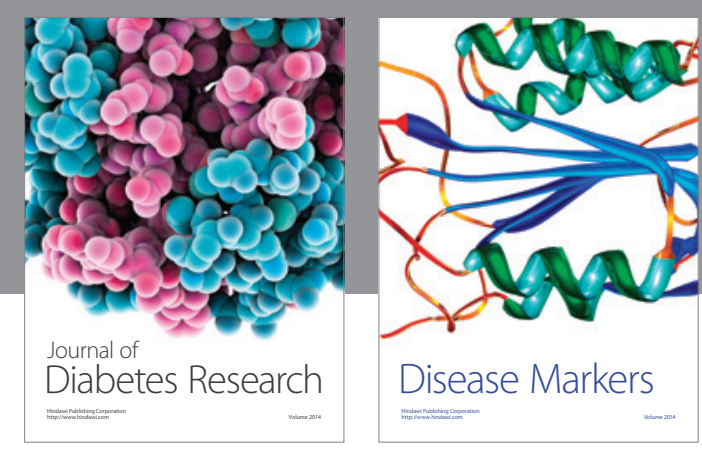

Disease Markers
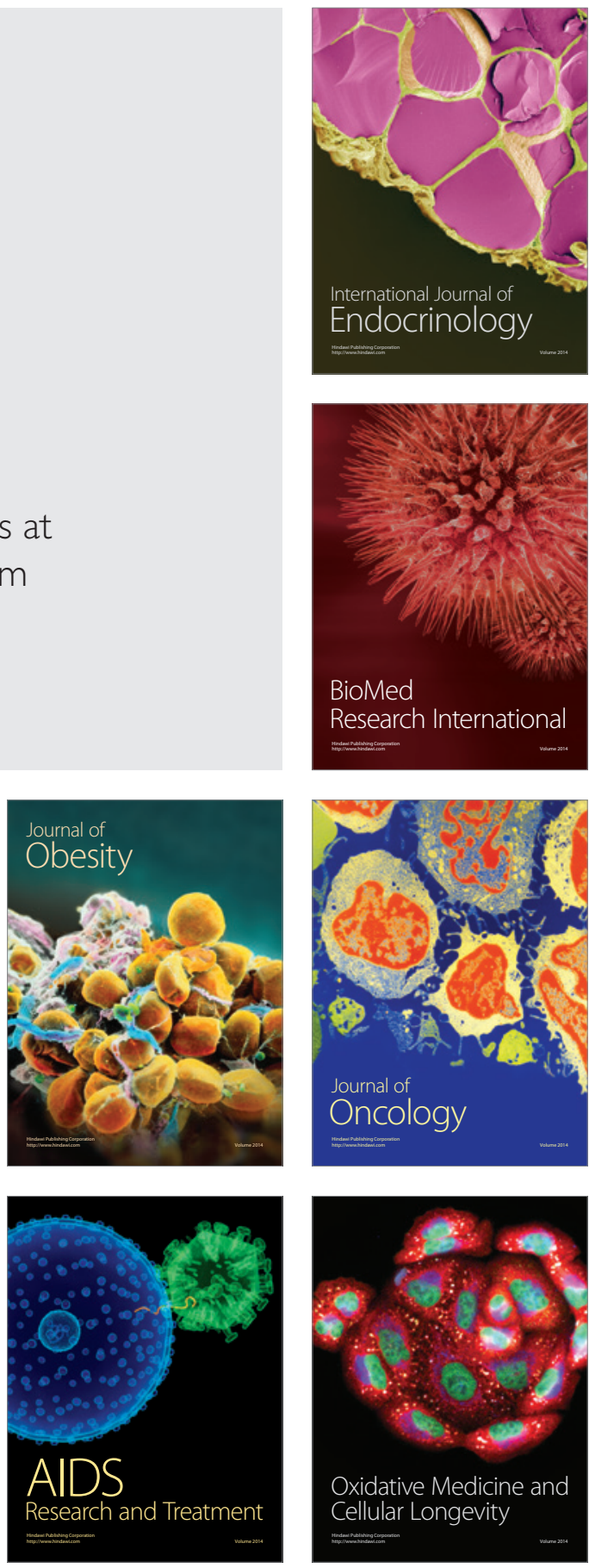